\title{
ARTICLE
}

\section{Deception-Based Hermeneutical Injustice}

\author{
Federico Luzzi (ib \\ University of Aberdeen, Aberdeen, UK \\ Email: f.luzzi@abdn.ac.uk
}

(Received 29 July 2020; revised 8 January 2021; accepted 28 January 2021)

\begin{abstract}
I argue that patients who suffer genital surgery to 'disambiguate' their sexual anatomy, a practice labelled 'intersex genital mutilation' (IGM) by intersex advocates, can be understood as victims of hermeneutical injustice in the sense elaborated by Miranda Fricker. This claim is clarified and defended from two objections. I further argue that a particular subset of cases of IGM-based hermeneutical injustice instantiate a novel form of hermeneutical injustice, which I call deception-based hermeneutical injustice. I highlight how this differs from central types of hermeneutical injustice in the literature and trace its harms.
\end{abstract}

Keywords: Hermeneutical injustice; intersex; intersex genital mutilation; epistemic injustice

\section{Introduction}

This paper has two aims. First, to elaborate and defend the claim that intersex genital mutilation (IGM) - i.e. surgery that aims at 'disambiguating' a person's sexual anatomy and that is not motivated strictly by physical health concerns - can underpin hermeneutical injustice, as described by Miranda Fricker (2007, 2013, 2016, 2017). I advance this claim and defend it from a challenge that seemingly precludes this possibility. In so doing, one dimension of the versatility of the concept of hermeneutical injustice comes to light, namely the fact that wrongs suffered by epistemically immature subjects can be included among the range of experiences that are capable of grounding hermeneutical injustice. My second aim is to argue that a subset of cases of IGM underpin a novel form of hermeneutical injustice, which I call deception-based hermeneutical injustice. I distinguish this from other forms of hermeneutical injustice in the literature and trace its harms. The subset of cases of IGM on which I focus illustrate the importance of distinguishing between the conceptual and empirical elements required for an adequate understanding of a social experience. Being mindful of this distinction allows us to see how select individuals may be crucially responsible in upholding deceptionbased hermeneutical injustice. This point puts pressure on Fricker's repeated claim that hermeneutical injustices are merely structural wrongs for which no specific individual or set of individuals can bear responsibility.

The paper proceeds thus: in section 1 I outline the concept of hermeneutical injustice. In section 2 I introduce relevant considerations concerning intersex conditions and IGM. In section 3 I argue that IGM can underpin hermeneutical injustice and defend this thesis from two objections. In section $4 \mathrm{I}$ argue, by contrast with extant forms of 
hermeneutical injustice, that a subset of IGM-based cases of hermeneutical injustice illustrate a new form of hermeneutical injustice, and trace its harms and theoretical implications in section 5 .

\section{Hermeneutical injustice}

In the closing chapter of Epistemic Injustice, Miranda Fricker describes hermeneutical injustice as an injustice that occurs against the backdrop of a social group being unfairly limited in their ability to develop, shape and contribute to the collective tools for interpreting social experience. Fricker dubs this unfair limitation hermeneutical marginalisation. Hermeneutical injustice arises when as a result of such marginalisation, an important social experience of someone who belongs to the hermeneutically marginalised group cannot be properly understood. In Fricker's definition, hermeneutical injustice is 'the injustice of having some significant area of one's social experience obscured from collective understanding owing to hermeneutical marginalization' (2007: 158).

This abstract profile of hermeneutical injustice is helpfully illustrated by Fricker's central case. Before the concept of sexual harassment was developed and widely adopted, many women were victims of a range of behaviours in the workplace which now would be confidently classified as sexual harassment, but which at the time were either confidently misclassified as innocuous forms of behaviour, or else were not met with a clear conceptual classification. Even forms of harassment at the extreme end of the spectrum, such as unwanted physical contact of a sexual nature from men, often would have been deemed mere flirting or 'joking around', and women who voiced their opposition to this behaviour might have been described as lacking a sense of humour' (2007: 153). According to Fricker, not only were these women the victims of the moral injustice of sexual harassment, but also the victims of hermeneutical injustice. This is due to two interlinking factors. Firstly, women were cut off from fully understanding such behaviour, primarily because of the unavailability of the concept of sexual harassment at the time, a concept that only came into existence and into broad acceptance through women's significant efforts (e.g. through consciousness-raising meetings, support groups, and political activism). That this concept is now part of the common pool of resources for interpreting experience allows us to readily identify its instances today. Before this, however - and this is the crucial second ingredient - women were hermeneutically marginalised: according to Fricker, their unjust exclusion from, or diminished access to, roles and professions that would likely have allowed them to delineate the concept of sexual harassment and have it accepted into the shared hermeneutical resource - professions such as politician, lawyer, journalist, businesswoman - obstructed the development and adoption of that concept (2007: 152). Thus, hermeneutical injustice consists in the failure, both by the victim of sexual harassment and by those around her, to understand her as a victim of sexual harassment. This failure is ultimately caused by women's unfairly limited ability to equitably contribute to the collective toolkit of intepretive resources.

In delineating hermeneutical injustice this way, Fricker recognises that knowledge is essentially a social enterprise, and that the prejudicial exclusion of social groups from the production of the epistemic tools used for interpreting experience can bring epistemic damage. The problem is made worse by the fact that prejudice not only causes epistemic exclusion, but is also reinforced by it: women attempting to communicate the wrong of sexual harassment without being able to rely on an adequate shared conception of this wrong may come across as confused and untrustworthy testifiers to members of more dominant social groups (i.e. men). This in turn can reinforce, in the eyes of some men, the stereotype of women as incompetent or unworthy epistemic 
contributors and can in turn lead to a greater entrenchment of their exclusion from roles of epistemic influence (2007: 159-60).

For our purposes it is important to note a further point about the apparent range of experiences that can ground hermeneutical injustice. According to Fricker, the essential and distinctive ('primary') harm of hermeneutical injustice is

situated hermeneutical inequality: the concrete situation is such that the subject is rendered unable to make communicatively intelligible something which it is particularly in his or her interests to be able to render intelligible. (Fricker 2007: 162, original emphasis)

This harm is for Fricker non-contingent. Unlike harms she labels 'secondary' - which may or may not follow from hermeneutical injustice and which may include a variety of epistemic and practical costs - situated hermeneutical inequality must be a product of an injustice if that injustice is to count as hermeneutical. One implication of this conception of the primary harm, which is not commonly noted in discussions around hermeneutical injustice, seems to be that it excludes the possibility that harms suffered by epistemically immature agents can ground hermeneutical injustice. As we will see, ultimately this point does not truly follow from Fricker's account, but it seems to draw support, at least at first blush, from the following point: while an epistemically immature agent, such as a baby, may very well be the victim of morally bad behaviour that is at a particular moment in history ill-understood as morally acceptable due to the inadequacy of existing collective hermeneutical tools and the hermeneutical marginalisation of the social group the infant belongs to, it is nonetheless implausible to suggest that in such cases epistemically immature agents themselves are 'rendered unable to make communicatively intelligible' something which it is in their interests to render intelligible. To elaborate: it seems implausible that infants would have been able to understand their experience of being the victim of some morally dubious behaviour if there had been no marginalisation-driven widespread lack of understanding of the wrong they suffer; for even in the absence of this widespread gap in understanding, the infant would have been incapable of understanding their particular experience due to their epistemic immaturity. The victim's lack of well-developed epistemic capabilities trumps hermeneutical marginalisation as the principal cause for the victim's lack of understanding. In this sense, there seems to be an important contrast with Fricker's central case, where it seems plausible to say that if the right concept had been available at the time, victims of sexual harassment before the 1970s would have been capable of understanding their experience properly. It seems, then, that Fricker's definition of its primary harm as rendering the victim unable to understand their experience precludes the possibility that harms suffered by victims who are epistemically immature can ground hermeneutical injustice. I will return to this matter below to argue that despite this point, it is possible for harms suffered by immature epistemic agents to ground hermeneutical injustice as defined by Fricker; but it is worth raising this matter early and bearing it in mind as we examine considerations related to intersex genital mutilation (IGM) which is our next task.

\section{Intersexuality and IGM}

Before discussing intersex conditions, a note on nomenclature is in order. Key terms in the literature and debate around the treatment of intersex patients are contested. Most notably, the medical term 'disorder of sex development' or 'DSD', introduced by the medical community after the 2005 International Consensus Conference on Intersex, 
is considered by many intersex patients to be needlessly and inappropriately pathologising. ${ }^{1}$ This is because the word 'disorder' suggests deviation from order and normality, whereas many intersex patients understand their bodies as perfectly normal, although exhibiting statistically infrequent sexual anatomies. ${ }^{2}$ Others, including patients and allies, embrace 'DSD', either because they see its use as an essential step in engaging positively with the medical community and bringing improvements to the treatment of intersex patients, or because some prefer a medicalised term to understand their experience (Dreger and Herndon 2009). Here, I will use the term 'intersex', due to its wider use in the non-medical literature to which this paper belongs. By using this term, however, I do not intend to suggest that all those who are affected by an intersex condition prefer or are fully comfortable with this term, or that they identify as intersex. As will be noted below, we should acknowledge the wide variety of views among intersex patients regarding their conditions, their preferred nomenclature, the treatment they receive, and even whether they reject the binary view of sex with which intersex conditions seemingly conflict (Meyer-Bahlburg et al. 2004; Davis 2014, 2015).

With these points in mind, we can think of intersex variations and conditions as those which entail sexual anatomies that do not conform to what are commonly considered typical conceptions of maleness and femaleness. Before encountering information regarding intersex conditions, it is common to believe that (i) all humans belong to one of two mutually exclusive and exhaustive readily identifiable sex categories (female and male), and (ii) that in each individual human being, various primary and secondary sex markers such as chromosomal patterns, sexual organs, genitalia, breast development, hormonal levels and facial hair, neatly align according to which of the two sexes one belongs to. Call the combination of (i)-(ii) the traditional view. Intersex conditions contradict the traditional view. Such conditions imply varying permutations of sex markers, which are combined across what is traditionally deemed to be the male/ female divide. Intersex conditions come in a diverse range and have widely varying physiological aetiologies and anatomical manifestations (Kemp 2006: 6). To mention only three examples from this wide range: persons with complete androgen insensitivity syndrome (CAIS) have a typically male XY chromosomal pattern, undescended testes, no womb, and an outward physical appearance that would be deemed clearly female; people with Klinefelter syndrome have an XXY chromosomal pattern - neither the typically male XY nor the typically female XX - low levels of testosterone, small male genitals, some breast development and overall male outward appearance; those with congenital adrenal hyperplasia $(\mathrm{CAH})$ have ambiguous genitalia, irregular periods, early puberty and facial hair. Other conditions bring different combinations of primary and secondary sex markers.

Intersex conditions that entail ambiguous genitalia, as well as those that entail combinations of gonads and genitals that do not align according to the traditional view (e.g. internal testes and vagina), will be of particular relevance to my discussion, for it is these conditions that in many cases have been treated by 'disambiguating' surgery. The motivation for this treatment stems ultimately from the perceived need to ensure that the patient be able to live their life in compliance with the female/male categorisation implied by the received view, and is in no small part due to the influence and legacy

\footnotetext{
${ }^{1}$ See for example, https://oiiinternational.com/, http://oiiuk.org/697/why-we-do-not-use-disorder-of-sexdevelopment/, Diamond and Beh (2006), Davis (2015) and Merrick (2017), who argues that this labelling is evidence of testimonial injustice.

${ }^{2}$ Estimates of the frequency of people with intersex conditions vary substantially, from as little as $0.018 \%$ (Sax 2002) to as much as $4 \%$ (Sanders et al. 2011) of the general population. Partly this variation is due to disagreement over the precise range of anatomies that should count as intersex.
} 
of John Money's treatment protocol for intersex conditions. According to this protocol which was dominant in the US in the latter half of the twentieth century and whose influence, although not uncontested, has continued beyond (Karkazis 2008) - it was important to ensure that a baby born with ambiguous genitalia or with combinations of gonads and genitals that did not align to the traditional view, had their sexual anatomy 'corrected' so as to correspond with either typical male or typical female anatomy. The direction in which the 'disambiguation' took place depended on the particular sexual anatomy of the patient, and on whether feminising or masculinising surgery was expected to be more successful in producing anatomies similar in appearance and function to typical male or female anatomies. The gender of the child's rearing was then aligned with the chosen sexual category. Importantly, clinicians following this protocol believed that surgery should be done at an early age, not least to alleviate the anxieties of parents who were uncertain of their child's sex, and especially in order to avoid the psychological damage which it was presumed patients would suffer if they became aware of their atypical sexual anatomy (Conn et al. 2005; D'Alberton 2010). To be clear, such surgeries were far from invariably successful as one-off interventions to settle the child's sexual anatomy and guarantee proper sexual function: particularly in cases of ambiguous genitalia, these interventions were often made with no regard for the child's future capacity for sexual sensation and compromised the possibility of the subject experiencing pain-free sexual intercourse later in life; further, such interventions often required follow-up invasive treatment (including vaginal dilation and/or further surgery), as the child developed through childhood and puberty (Alizai et al. 1999; Minto et al. 2003; Creighton 2004). In addition to these negative elements of surgical treatment, nonsurgical treatment of intersex patients could involve unethical, stigmatising practices such as 'grand-rounds' where, without consent, young patients were subjected to medical scrutiny of their anatomy by groups of medical practitioners and trainees.

The experiences of patients who suffered such surgery in their infancy make it easy to understand why intersex advocates strongly contest this practice, and why some have labelled 'intersex genital mutilation' those surgical interventions that are not strictly required for medical health reasons, that are not consented to by the patient, and that are performed primarily for cosmetic or social reasons ultimately grounded in the perceived need to comply with the traditional view. For example, Bo Laurent recounts:

My parents actually raised me as a boy for a year and a half, and then they found their way to a different set of doctors who decided that I was not 'really a boy' but I was 'really a girl.' I actually think that I wasn't really either but the second set of doctors told my parents that they could perform surgery that was going to make certain that I would come out normal. The surgery was surgery that basically destroyed my clitoris and the possibility of satisfying future sexual function. They told my parents to move to another town and not tell anybody where they went, and not to ever tell me what happened. The outcome of that has been one that was really harmful for me and for my family. It undermined the ability for my parents and me to have a relationship over the long term. ${ }^{3}$

This testimony makes clear the physical damage Laurent suffered. But it is also important to highlight, as the last sentence in the cited passage indicates, that the damage wrought by such treatment was also psychological (Karkazis 2008: 219). In regrettable irony, medical practitioners' and parents' efforts to deny children knowledge of their

\footnotetext{
${ }^{3}$ https://www.interfaceproject.org/transcript-bo-laurent.
} 
intersex conditions, grounded in good-faith attempts to shield them from the psychological damage they would allegedly incur if they were made aware of this, in many cases caused and sustained a psychologically toxic atmosphere of secrecy and shame. This is evident from several sources of testimony. For example:
Although the doctors have claimed that knowing the truth would make me self- destructive, it was not knowing what had been done to me - and why - that made me want to die. (Angela Moreno, quoted in Coventry 1998)
The lies and deception that have occurred throughout my life have taken their toll on me, making me very insecure and unwilling to trust people, especially those close to me. ('Graham' quoted in Hester 2006: 54)
They [the parents] were advised by my paediatric endocrinologists to tell me I had a simple hernia when, as a young child, I discovered the abdominal scar just above my pubic region. They were then to say nothing until the eve of puberty, at which time they should tell me that I had 'twisted ovaries' which had been removed at birth to prevent them from becoming cancerous. ... I was worried that my 'ovaries' were not removed as a prophylactic measure to prevent cancer, but that I instead actually had cancer and that my parents weren't telling me the truth. (Morris 2006: 4)

These testimonies illustrate the physical and psychological damage suffered by patients at the hands of medical professionals during medical treatment of intersex conditions. In recent decades IGM has emerged as a human rights issue and the medical community have acknowledged the need to address this contested practice. One milestone in this regard is the Consensus Statement on Treatment of Intersex Disorders (Lee et al. 2006), which for the first time included intersex advocates in the process of developing treatment guidelines. The diversity in views towards genital surgery on the part of intersex patients should also be noted, with some patients expressing satisfaction with their surgery, despite having been too young to give informed consent. ${ }^{4}$ This should not be wholly surprising, given the variety of intersex conditions, the varying degree to which anatomies can differ from what are deemed typical female and male anatomies, improvements in surgical techniques, and the diversity of the environments in which patients grow up.

Despite these seemingly positive notes, the situation is still far from satisfactory for many intersex advocates. Firstly, the Consensus Statement itself failed to provide an adequate platform for advocate voices to be heard; ${ }^{5}$ secondly, the Statement only provides guidelines; as a result, medical standards of care that prevent non-medicallynecessary surgery are still not in place in the US, ${ }^{6}$ and many clinics continue to conduct

\footnotetext{
${ }^{4}$ See e.g. Meyer-Bahlburg et al. (2004).

${ }^{5}$ The degree of influence exerted by the two participating intersex advocates involved was strongly curtailed by the structure of the meeting, which was established in advance exclusively by clinicians. This structure confined the advocates to workgroups that did not deal with contentious issues such as surgery, outcome data and medical management. Additionally, the advocates were unable to finalise the statement draft before the end of the meeting, and some of the agreed points were not included in the final draft. Only some of their requests for reinserting these points into the document were accepted prior to its publication. See Karkazis (2008: 319-20) for further details. Moreover, the very term 'disorders of sex development' chosen by the medical establishment to replace the terms 'intersex' and 'hermaphroditism' is deemed by many to still be unfairly pathologising and stigmatising.

${ }^{6}$ As the Intersex Society for North America (now Accord Alliance) wrote about the Consensus Statement: 'This is ISNA's dilemma: we finally have consensus on improvements to care for which we have advocated for so long, but we lack a consistent way to implement, monitor, and evaluate them. At
} 
such operations, driven by the perceived need to have the child conform to conceptions of typical maleness/femaleness and avoid social stigma:

[D] espite evolving standards of care, the establishment of multi-disciplinary "DSD teams," distaste for discrimination, and an increasingly visible public debate over informed consent and medical necessity, many doctors continue to misinform parents of intersex children and pressure them into choosing unnecessary cosmetic surgeries on their children. (Human Rights Watch 2017a).

In sum, it is undeniable that many of those who underwent 'disambiguating' surgery suffered substantial harm, compounded by stigma and secrecy surrounding their condition. And it is clear that many unnecessary surgeries of this kind continue to this day. Having outlined some central aspects of intersex conditions and the history of their treatment, I move on to consider the claim that IGM grounds hermeneutical injustice. This claim, I argue, is straightforward in cases where the patients are epistemically mature agents; I contend that, contrary to initial appearances, it is also defensible in cases where patients are too young at the time of surgery to suffer epistemic damage.

\section{IGM underpins hermeneutical injustice}

Before we begin assessing how IGM may interact with hermeneutical injustice, a few words are in order on why the overlap between the two concepts is worth investigating. Reflecting on the central case of hermeneutical injustice proposed by Fricker suggests that there is common ground between it and issues surrounding IGM, and that this common ground is substantial enough to make an investigation prima facie worthwhile. A key shared element between the central case of sexual harassment and IGM is that in both contexts a moral shift has occurred, or is ongoing, which exposes practices that were once widely misunderstood to be morally acceptable as in fact morally wrong. While sex-disambiguating surgery performed without informed consent for merely cosmetic or psychosocial reasons used to be widely deemed appropriate in the treatment of intersex patients, there is increasing recognition now that such surgery is inappropriate. Similarly, a moral awakening in the 1960s and 70s caused a widespread shift in attitude that brought society to recognise unacceptable behaviour formerly considered innocuous for what it really was: sexual harassment. This constitutes evidence that in both cases, a particular shortcoming in the collective hermeneutical resource - a 'conceptual lacuna' in Fricker's terminology - hindered a proper understanding of certain wrongs as wrongs, both on the part of victims and on the part of perpetrators. Thus, Fricker's diagnosis of her central case, as arising in virtue of a conceptual lacuna where the concept sexual harassment ought to have been, finds a close parallel in the diagnosis that for a long spell an analogous gap existed which the concept intersex genital mutilation eventually filled. Moreover, and crucially, in each case this shortcoming arose due to inequalities in the affected groups' relative power to shape discourse over the wrongs inflicted on them: the claim that women were marginalised in the production of hermeneutical tools for understanding sexual harassment enjoys comparable plausibility to the claim that intersex patients and advocates were (and continue to be) hermeneutically sidelined in discourse that shaped (and continues to shape) the collective understanding of intersex conditions and their proper medical treatment. The very existence of a history of intersex advocacy groups stands as evidence of hermeneutical

present, the new standard of care exists as little more than ideals on paper, thus falling short of its aim to improve the lives of people with DSDs and their families'. (http://www.isna.org) 
marginalisation (there is little need for advocacy in situations of hermeneutical equality); and the difficulty such groups encountered in having their point of view taken seriously by the medical establishment is well-documented. ${ }^{7}$ The conditions for hermeneutical injustice are all in place, and it is thus plausible to believe that IGM can ground hermeneutical injustice. Concretely: patients subjected to IGM when this was ill-understood as acceptable - indeed, recommended - medical treatment were unable to see themselves as victims of a moral wrong, due to prevailing misconceptions surrounding the appropriateness of such surgery - misconceptions which intersex patients themselves had little hope of eradicating from the pool of interpretive resources used by the medical community.

But a significant challenge contends that we should restrict this claim only to those who suffered IGM as epistemically mature agents. Recall that in Fricker's definition, victims of hermeneutical injustice must suffer the primary harm of being 'rendered unable to make communicatively intelligible something which it is particularly in his or her interests to be able to render intelligible' (2007: 162, my emphasis). It is true to say of infants subjected to IGM that they are not able to articulate and make intelligible (to themselves or others) a part of their experience that it is in their interests to understand. However, this cognitive limitation does not arise because of hermeneutical marginalisation, as hermeneutical injustice demands; it occurs instead in virtue of the fact that these victims of IGM have yet to develop the cognitive capacities to understand any experience. In frustrating the victim's ability to successfully exercise their epistemic abilities, epistemic injustice requires that the victim have those abilities in the first place. In this specific case, however, hermeneutical injustice seemingly has no traction: the epistemic 'harm' it would have brought is no real harm at all; it simply leaves things as they are, for it is implausible to say that the infant's efforts to adequately understand their surgery are frustrated by hermeneutical injustice. After all, no such effort can be made. The victim's inability to understand their surgery is to be chalked up to their underdeveloped epistemic capacities and not to any thwarting conceptual lacuna. This point seemingly jeopardises the possibility that IGM performed on infants could ground hermeneutical injustice, and threatens to generalise to other cases where a diagnosis of hermeneutical injustice seems apt, but the subject of the experience in question is very young. The existence of hermeneutical injustice thus seemingly depends on the underpinning ill-understood wrong being experienced by an epistemic agent who is mature enough to make a serious - albeit frustrated - attempt at understanding.

An additional worry for the claim I seek to defend is that hermeneutical injustice as defined by Fricker entails 'having some significant area of one's social experience obscured from collective understanding owing to hermeneutical marginalisation' (2007: 158, my emphasis). But, one may wonder, what is the experience allegedly obscured in cases of IGM performed on infants? ${ }^{8}$ Surgery itself typically requires full anaesthetisation; so how can the infant's experience be the target of misunderstanding? Additionally, the fact that the infant is too young to later remember events surrounding

\footnotetext{
${ }^{7}$ For an excellent, detailed exploration of how intersex patients and advocates have been hermeneutically marginalised, see Merrick (2017). As part of a rich exploration of the epistemic injustices suffered by patients with intersex conditions, Merrick observes that IGM underpins hermeneutical injustice. However, Merrick does not examine the claim in detail, and in particular does not explore, as I do here, whether it is possible to count the experiences of immature epistemic agents who suffered IGM as underpinning hermeneutical injustice, nor how this form of hermeneutical injustice differs from others in the literature.

${ }^{8}$ Thanks to Colin Johnston for pressing me to consider this point.
} 
the surgery seems to preclude the possibility that material offered by memory plausibly counts as the target ill-understood experience. The case seems importantly disanalogous to Fricker's central example of hermeneutical injustice involving Carmita Wood, who clearly experiences and can remember (although she cannot accurately comprehend) the unpleasant behaviour of which she is the victim.

Despite these difficulties, this objection can be addressed, or so I will argue. The first challenge here is to articulate an adequate view of who the victim of hermeneutical injustice is. The second challenge is to explain in what sense those who suffer IGM as infants can be said to have an experience of theirs obscured from collective understanding. I argue that meeting these challenges underlines the versatility of Fricker's conception of hermeneutical injustice. An important further theoretical benefit is that it brings into view a novel variety of hermeneutical injustice.

\subsection{Who is the victim?}

A notable feature of some central cases of hermeneutical injustice, including the case of Carmita Wood, is that hermeneutical injustice is parasitic on some logically prior moral wrong. Being the victim of a moral wrong is clearly something that one has an interest in recognising and communicating; and the essential harm that one suffers from hermeneutical injustice is, to rehearse Fricker's definition

situated hermeneutical inequality: the concrete situation is such that the subject is rendered unable to make communicatively intelligible something which it is particularly in his or her interests to be able to render intelligible. (2007: 162, original emphasis)

In central cases like Carmita Wood's, hermeneutical injustice adds insult to injury by making someone who is already the victim of a wrong (e.g. sexual harassment) the victim of a further injustice - hermeneutical injustice - which consists in their hermeneutical-marginalisation-driven inability to make sense of and communicate their victimhood. This suggests that the victim of the hermeneutical injustice and the victim of the moral wrong are one and the same. It is tempting to draw the further conclusion that the hermeneutical injustice always arises more or less at the same time as the moral injustice which grounds it is suffered.

But this need not be so. Indeed, as Fricker herself acknowledges in the central case of Carmita Wood, hermeneutical injustice occurs at the moment in which Wood tries and fails to articulate on her unemployment insurance form the reason why she left her job. ${ }^{9}$ In other words, a substantial amount of time has elapsed between Wood suffering sexual harassment and her suffering this instance of hermeneutical injustice. As the following passage from Fricker makes clear, her account explicitly allows for a temporal lapse between the occurrence of the hermeneutical injustice and the moral wrong underpinning it.

The background condition for hermeneutical injustice is the subject's hermeneutical marginalization. But the moment of hermeneutical injustice comes only when

\footnotetext{
${ }^{9}$ This is not to say that it is the only instance of hermeneutical injustice suffered by Carmita Wood: it is likely that Wood made several attempts to understand such behaviour before she was asked to explain her reasons for quitting her job on her unemployment form. Fricker's account entails that at the moment of each failed attempt at understanding the experience of sexual harassment she underwent, Wood was the victim of a distinct instance of hermeneutical injustice.
} 
the background condition is realised in a more or less doomed attempt on the part of the subject to render an experience intelligible, either to herself or to an interlocutor. The hermeneutical inequality that exists, dormant, in a situation of hermeneutical marginalization erupts in injustice only when some actual attempt at intelligibility is handicapped by it. (Fricker 2007: 159)

The idea, then, is to model the case of infant IGM along the lines of Wood's case: just as Wood can be the victim of hermeneutical injustice a substantial amount of time after she was the victim of the moral wrong of sexual harassment, so an infant who is the victim of IGM is a target of hermeneutical injustice once they have matured into an epistemic agent with the cognitive capacities that - but for the limitations of the available hermeneutical resources - would enable them to make sense of and communicate their being the victim of IGM. The hermeneutical injustice surfaces only when, years after surgery, the victim attempts to understand the experience of having been subjected to IGM. Thus understood, hermeneutical injustice reveals itself to be a versatile enough notion to countenance IGM suffered by infants as underpinning some of its instances.

\subsection{Experience}

But a second apparent difficulty for the view that IGM underpins hermeneutical injustice now emerges. Suppose that the victim of IGM, once they have reached epistemic maturity, can be the target of hermeneutical injustice, on account of the putative fact that they are thwarted in their attempt to understand their experience of IGM victimhood. One might now wonder exactly what this experience of IGM victimhood amounts to: for there are undeniably differences between the interpretive efforts of Carmita Wood in coming to grips with her experience, on the one hand, and the adult who was subjected to IGM as an infant, on the other. When Wood struggles to understand her experience of being sexually harassed, she has epistemic access via memory to key features of that experience (what happened, where it happened, who perpetrated it) and to informative aspects of that experience's unpleasant phenomenology. By contrast, the epistemically mature adult who was the victim of IGM in their infancy lacks mnemonic access to anything of the sort: there is simply no material there brought forth by memory that is in any way puzzling and of which sense must be made. The critical question is whether, despite these undeniable differences, it is plausible to say that the adult who was a victim of IGM suffers hermeneutical injustice; that is, whether it is plausible to say they have been cognitively incapacitated in their effort to understand their experience of IGM, even in the absence of any mnemonic access to it. Whether the case meets the definition depends on what we take experience, in the relevant sense, to require.

While Fricker has not discussed this matter, her conception of hermeneutical injustice can encompass cases where the victim has no direct memory of the target experience. Imagine one could, by pressing a button on a portable device, remove selected memories from someone's mind and replace them with a chosen set of others. Imagine also that a sexist society in which the concept of sexual harassment has yet to be developed recognises that women who are subjected to what is commonly deemed unproblematic 'joking around' in the workplace - but which in a more enlightened society would be recognised as sexual harassment - often leads women to leave their jobs, thus bringing substantial negative consequences to the economy. In order to retain women's valuable workforce contribution, this society deems it expedient to replace the memories of women who complain of unwanted attention from male colleagues with memories of unproblematic, routine, non-'joking around' workplace behaviour. 
Suppose now that a woman had all memories of her harasser's behaviour replaced by this method with coherent but fake memories of her harasser behaving in a morally respectable fashion towards her. It seems evident that even if she lacks any memory of the sexual harassment she was subjected to, she suffers hermeneutical injustice she is prevented from understanding an important aspect of her social experience, at root because of women's hermeneutical marginalisation. The observation that this person has 'some significant area of one's social experience obscured from collective understanding owing to hermeneutical marginalization' (Fricker 2007: 158), as Fricker's definition has it, is compelling. This supports the point that direct memory of an experience is not needed in order for someone to be a victim of hermeneutical injustice.

One possible objection involves noting that this scenario, like the original case of Carmita Wood, involves a subject who consciously experiences the wrong that underpins hermeneutical injustice (i.e. sexual harassment). However, an infant who is subjected to IGM does so under general anaesthetic and therefore never experiences such surgery. How can it be claimed, then, that a social experience of theirs is obscured from collective understanding, as required if hermeneutical injustice is to have occurred?

One way of circumventing this objection is to observe that victimhood of a wrong which one does not consciously experience may still leave traces that can be consciously experienced at a later time. Most relevantly, in the case of IGM the adverse physical effects of surgery - scar tissue, the reduction in capacity to experience sexual pleasure, the follow-up treatment that is often required - will be marks of the wrong that remain within the epistemic purview of the victim well beyond the point when IGM is performed. It is plausible to think that the victim who is deceived into misconstruing these marks as evidence of something other than IGM will have their experience - of having scar tissue, of being less capable of experiencing sexual pleasure, of having follow-up treatment - placed beyond reach of a full and accurate understanding, since they will lack a full understanding of their true cause. Selecting these as the experiences which, owing to hermeneutical marginalisation, are not understood by the victim allows us to countenance IGM victims as victims of hermeneutical injustice. Admittedly, whether early-days IGM can ground hermeneutical injustice becomes a contingent matter, dependent on whether in the wake of surgery there are after-effects and traces which the subject experiences and that are available as the targets for (mis)understanding. But IGM routinely leads to perceptible consequences on the bodies on which it is performed.

The point can be broadened to draw a more general conclusion about hermeneutical injustice grounded in wrongs suffered by epistemically immature subjects. It is possible to countenance wrongs suffered by epistemically immature subjects as grounding hermeneutical injustice whenever such wrongs leave some kind of trace - whether in the form of physical features, memories, or other - that is later observable by the subject, once they have reached the epistemic maturity required to make an attempt at understanding such traces. When such attempts are made and thwarted, hermeneutical injustice may arise.

\section{Deception-based hermeneutical injustice}

Having established that it is possible to countenance IGM performed on epistemically immature subjects as properly underpinning hermeneutical injustice, I wish to further argue that a subset of cases of IGM ground a distinctive and particularly insidious form of hermeneutical injustice. This form of hermeneutical injustice engages with Fricker's claim that individual agents cannot be held responsible for hermeneutical injustice, which is instead a purely structural injustice. 
The central aspect of IGM that is relevant to our purpose here is the widespread practice, on the part of doctors and parents, of concealing from the victim the true nature of their condition and of their treatment in an attempt to shield them from the social stigma associated with having sexual anatomy at odds with the traditional view. Evidence of this practice is to be found in many first-personal accounts of patients with intersex conditions, as prior quotations illustrate; but it is also acknowledged by medical practitioners. As two doctors who are also parents of a child born with an intersex condition explain:

What we had been taught in medical school was that these women were never to be told of their diagnosis, of their [XY] chromosomes, or that they had [undescended] testes, because it would be so devastating to them that they would commit suicide.

What parent is going to convey a piece of information that might lead their kid to hurt themselves? ${ }^{10}$

The widespread medical practice of condition concealment meant that it could take years of effort for patients with intersex conditions to elude this orchestrated misdirection and uncover their real medical diagnosis. Consider again, for instance, the previously cited case of Sherri Morris, who was born with no womb and no ovaries, with internal testes and female genitalia, and had an outward female appearance (Morris 2006). Morris's testes were removed in early infancy. ${ }^{11}$ Morris's endocrinologist advised her parents to explain the scarring caused by surgery with the fabricated story of a hernia, and the absence of womb or ovaries with a lie concerning 'twisted ovaries' which necessitated surgical removal in her early life due to the risk of their becoming cancerous. Morris eventually discovered that she was born with an intersex condition, but it is far from clear that this discovery was inevitable. Morris was helped by the fact that the story she was told conflicted with other contingent symptoms, and by access to medical resources in her university library that allowed her to make progress in discovering the truth. Similarly, it was access to the books in the university library he was working in that allowed Daniel Johnson to discover that he was born with partial androgen insensitivity syndrome (PAIS). This occurred when he chanced upon a copy of John Money's Man and Woman, Boy and Girl and, seeing pictures of bodies resembling his own, decided to read it (Karkazis 2008: 226).

Discovering one's true diagnosis was thus sometimes the result of fluke or happenstance. While in more recent times such discoveries have been aided by far-reaching communication tools that help intersex patients access reports of the experience of others (e.g. the internet) and by a willingness to publicly discuss intersex conditions that were absent in recent decades, it is nonetheless clear that many victims of IGM were at some stage of their life kept in the dark about their intersex condition, given that the practice of concealment was widespread and information in the public sphere was sparse; it is even reasonable to believe that some people who suffered IGM may never have discovered the truth.

I will focus for the rest of my discussion on this category of victims of IGM - those who for some stretch of time are successfully misled by the fabrications of doctors and parents. Individuals in this group can be understood to be victims of a distinctive form

\footnotetext{
${ }^{10} \mathrm{Me}, \mathrm{My}$ Sex and I (BBC1 Scotland 2011).

${ }^{11}$ This was a standard practice motivated by the alleged risk of the testes becoming cancerous; there is now increasing recognition that the risk of cancer is minimal until adulthood is reached, when, crucially, the subject's consent to surgery can be obtained.
} 
of hermeneutical injustice, which we can call deception-based hermeneutical injustice. Similarly to other cases of hermeneutical injustice, this kind of injustice arises because the victim's incapacity to understand their victimhood of IGM is ultimately rooted in the hermeneutical marginalisation of intersex patients. By virtue of this marginalisation, the view of IGM as appropriate treatment was sustained by the medical establishment and by wider society. What makes this kind of injustice distinctive? To explain, in the next three sub-sections I will contrast this form of hermeneutical injustice with three key forms of hermeneutical injustice in the literature.

\subsection{Contrast 1: Fricker's central cases of hermeneutical injustice}

In the case of IGM under consideration, doctors and parents deliberately misdescribe past events which the victim was in no position to understand at the time of their occurrence, and of which they have no direct memory now that they have developed into epistemically mature agents and would be in a position to understand them (but for hermeneutical marginalisation). Thus, victims of this form of IGM do not feel the inadequacy of the interpretive tools at their disposal to make sense of their experience: if they are truly deceived, there is simply no sense, from their point of view, that their understanding is partial or inadequate.

In this way, deception-based hermeneutical injustice is clearly distinct from central forms of hermeneutical injustice discussed by Fricker, which see hermeneutical injustice arise out of a failure to understand someone's victimhood, where, significantly for our purposes, this injustice leaves the victim with an acute sense of discomfort and moral impropriety that does not surface to the level of full comprehension. Fricker calls this 'dissonance' between the victim's own views about their experience and the inadequate collective interpretive tools available to make sense of that experience. Think of Carmita Wood quitting her job because she feels that something is very much awry with her harasser's behaviour, despite not understanding fully the nature of the wrong and what makes it wrong; ${ }^{12}$ or of Wendy Sanford, described by Fricker as a mother with postnatal depression who is disoriented by her inability to understand what available interpretive resources incline her to see as personal failings as a mother, such as lack of joy in taking care of her child, but which are in fact the symptoms of a medical condition. In these instances of hermeneutical injustice, subjects whose experience is not fully comprehensible at least have some evidence that something is amiss, although due to crucial conceptual lacunae in the shared hermeneutical resource they have difficulty understanding and articulating exactly what is wrong.

\subsection{Contrast 2: 'Failed communication' cases of hermeneutical injustice}

Deception-based hermeneutical injustice is also distinct from a more inclusive concept of hermeneutical injustice which Fricker has explicitly espoused in more recent work. Fricker $(2013,2016,2017)$ makes clear that the notion of hermeneutical injustice can subsume cases proposed by several commentators (Mason 2011; Dotson 2012; Pohlhaus Jr. 2012; Medina 2013), where a marginalised social group develops adequate

\footnotetext{
${ }^{12}$ Note that Mason (2012) disagrees with this characterisation of Carmita Wood's situation, arguing that she understands her experience fully, and thus better than Fricker gives her credit for. If Mason is correct, then Carmita Wood does not suffer the dissonance Fricker highlights, and the case of Carmita Wood needs to be understood as instantiating a different kind of hermeneutical injustice. I discuss this kind of injustice in the next section, and contrast it with deception-based hermeneutical injustice. Thus, my argument in favour of the distinctiveness of deception-based hermeneutical injustice is independent of whether Fricker's or Mason's characterisation of Carmita Wood's epistemic situation is preferable.
} 
interpretive tools and thus achieves a successful understanding of an important aspect of their experience; but this understanding remains localised to that non-dominant community because dominant groups lack the interpretive tools required to understand. ${ }^{13}$ In these cases the victims are left in no state of dissonance; rather, they have an adequate conception of the moral wrong they are victims to, but crucially, '(owing to the collective hermeneutical gap pertaining to the wider community as a whole) [they] still cannot expect to communicate it successfully to significant social agencies ... in order to describe or protest the experience' (Fricker 2013: 1319). Oppressed groups may very well understand that some behaviour of which they are victims is wrong, but at the same time other groups (some of whom may actually benefit from such behaviour) fail to adopt the hermeneutical tools developed by the oppressed group - tools that would aid a collective proper understanding of that behaviour as a wrong. ${ }^{14} \mathrm{We}$ can call these 'failed-communication' cases of hermeneutical injustice.

But deception-based hermeneutical injustice, as it arises in the relevant cases of IGM, is different: its victims are not merely prevented from communicating an experience that they understand; its victims fail to achieve a correct understanding of the wrong they have suffered, and in fact endorse a mistaken understanding of their experience owing to misplaced trust in their parents and doctors. In this respect, it clearly differs from failed-communication cases of hermeneutical injustice described in the literature.

\subsection{Contrast 3: 'Internalised-misconception' cases of hermeneutical injustice}

Because victims of deception-based hermeneutical injustice endorse mistaken understandings of the target experience, this form of hermeneutical injustice exhibits important similarities with what may be called 'internalised-misconception' hermeneutical injustice, examples of which have been recently discussed by Katharine Jenkins (2017). ${ }^{15}$ Imagine a colleague of Carmita Wood's who, influenced by the widespread but mistaken understandings of her time, experiences what is in fact sexual harassment, and yet perceives it to be a perfectly acceptable and harmless form of flirting. She is unable to achieve an appropriate understanding of her experience as one of victimhood, due to her acceptance of common misconceptions about that behaviour. Those misconceptions are sustained and propagated through women's hermeneutical marginalisation. This colleague is thus the victim of a form of hermeneutical injustice. Like victims of deception-based hermeneutical injustice arising from IGM, she experiences no dissonance: to her, nothing about the behaviour in question is morally amiss; and like such victims, her social group's hermeneutical marginalisation contributes essentially to her inability to recognise her victimhood.

\footnotetext{
${ }^{13}$ Interestingly, as Fricker (2016) remarks, one of the three cases Fricker provides in her (2007) fits this profile: the character Joe Rose of McEwan's novel Enduring Love (McEwan 1998) understands his position as a victim of stalking but is unable to get the police to understand that he is the victim of a wrong.

${ }^{14}$ Both Medina (2013) and Pohlhaus Jr. (2012) argue that in the trial of Tom Robinson in Harper Lee's novel To Kill a Mockingbird hermeneutical injustice of this broader variety is at issue: the Black characters (including Tom Robinson) understand very well their own oppression and the hermeneutical injustice stemming from white people's staunch and wilful resistance to availing themselves of the interpretive resources that would enable them to come to an accurate picture of what really happened between Tom and Mayella. Such resources include the ideas - which are taboo in white society - that a Black man can feel sorry for a white girl and that a white girl can be sexually attracted to a Black man. The conception of this type of deliberate and entrenched 'white ignorance' is due to Charles Mills (2007).

${ }^{15}$ The cases Jenkins focuses on involve harmful and distorting rape/domestic abuse myths which are accepted by victims, who are thus unable to see themselves as victims of these crimes.
} 
Despite these similarities, there are two significant differences between deceptionbased hermeneutical injustice and internalised-misconception hermeneutical injustice which warrant a conceptual distinction. The first difference is that internalisedmisconception hermeneutical injustice, as Jenkins argues, arises from the divergence between, on the one hand, a particular concept as it is officially outlined in law or social institutions (the 'manifest concept') and, on the other hand, that concept as it is deployed by social groups 'on the ground' (the 'operative concept' - cf. Haslanger 2012). To explain using one of Jenkins's examples, domestic abuse as a manifest concept covers cases where the abuse is psychological, even though on the widespread and common understanding of domestic abuse, only physical forms of abuse count as domestic abuse. The divergence between the manifest and the operative concepts allow for the development of various domestic abuse myths, one of which is that the abuse must be physical. Because victims themselves often adopt the operative concept, unaware of its divergence from the manifest concept, they may fail to realise that the behaviour they experience constitutes domestic abuse.

By contrast, the deception-based hermeneutical injustice experienced by IGM victims does not involve a conceptual deficiency: the victim may very well reject the traditional view of sex and endorse an enlightened view of IGM that deems it a substantial wrong. What causes their inability to see themselves as victims, instead, is their being withheld empirical information: that they were born with an intersex condition and underwent IGM. So while it is essential that victims of internalised-misconception hermeneutical injustice operate with a defective concept of the ethical harm they suffer, victims of deception-based hermeneutical injustice need not do so. Their ignorance of their victimhood arises from a lack of empirical, rather than conceptual, knowledge.

A second difference, related to the first, is that unlike cases of internalisedmisconception hermeneutical injustice discussed by Jenkins, cases of deception-based hermeneutical injustice involve individual agents playing a crucial role in obscuring the victim's experience of IGM: doctors and parents make clearly identifiable, individual contributions to the maintenance of the victim's ignorance - unlike the broader hermeneutical marginalisation of intersex patients, which is the result of structural forces. Although they can be seen as acting in good faith, it is noteworthy that such individuals can reasonably be held responsible for their essential contribution to the victim's lack of understanding. This observation is significant against the backdrop of Fricker's claim that hermeneutical injustice is merely structural $(2007: 168,2016,2017)$, in the sense that it is simply the result of social-epistemic inequalities over which no select and easily identifiable individual or group of individuals holds responsibility.

In this connection, it is helpful to differentiate this aspect of deception-based hermeneutical injustice from the observation made by some commentators that we can appropriately hold individual interlocutors responsible for hermeneutical injustice if they are not duly sensitive to the possibility that a speaker who reports a seemingly unintelligible experience might simply lack the conceptual resources required to make this intelligible, because of hermeneutical marginalisation (Maitra 2010: 209-10, Medina 2013: 109-18). For example, Maitra imagines Carmita Wood attempting to communicate her discomfort to an unsympathetic colleague who considers any woman who is uncomfortable with men's behaviour in the workplace to be a 'nervous ninny'. This colleague counters Wood's reports by accusing her of prudishness. This hearer's response, Maitra argues, may convince Wood that she has overreacted and will further obscure her experience, thus contributing to hermeneutical injustice.

It is clear that this way in which individuals can contribute to hermeneutical injustice differs from the way in which the orchestrators of deception contribute to deceptionbased hermeneutical injustice. For the contribution that doctors and parents make to 
deception-based hermeneutical injustice, in the case related to IGM, is both proactive and intentional. It does not occur by way of responding unsympathetically to the victim's attempt to communicate a perceived wrong, in the context of a state of dissonance on their part. Rather, it involves taking the initiative in ensuring that the victim remains in an ill-informed state, typically by feeding the victims fabricated stories or diagnoses designed to be plausible enough for the victim to believe them. Relatedly, it is possible for an unsympathetic hearer to contribute inadvertently to the obfuscation of the victims' experience, as Carmita Wood's imagined interlocutor does. But in deceptionbased hermeneutical injustice the effort to obfuscate is part of a deliberate and harmful (if well-intentioned) plan to keep the victim in the dark.

The point that individuals contribute to deception-based hermeneutical injustice is worth emphasising. As Fricker's definition of hermeneutical injustice has it, the lack of understanding surrounding the victim's social experience must be due to hermeneutical marginalisation and may thus seemingly make hermeneutical injustice a merely structural wrong. However, as deception-based hermeneutical injustice illustrates, in some instances hermeneutical marginalisation makes a necessary but not sufficient contribution to maintaining the victim's lack of understanding, and this lack of understanding is also essentially supported by the actions of a small number of people. The possibility of this type of case can be understood by observing that an appropriate understanding of an experience does not only require suitable concepts, but also accurate empirical information to be interpreted through those concepts. The structural phenomenon of hermeneutical marginalisation serves to undermine the availability of the former. But in cases of deception-based hermeneutical injustice, the victim's lack of understanding is partly (but essentially) caused by some individuals' withholding from the subject accurate empirical information. In such cases, hermeneutical injustice depends on more than one factor, each of which makes a distinctive and necessary contribution to maintaining the victim's ignorance of the relevant experience. And since the actions of those who withhold empirical information from the victim are significant and necessary to maintaining the victim's lack of understanding, those individuals can be held to a significant degree responsible for hermeneutical injustice.

\section{The harms of deception-based hermeneutical injustice}

Deception-based hermeneutical injustice, then, is instantiated by the injustice suffered by victims of IGM who accept the stories fabricated to explain away its physical consequences. ${ }^{16}$ It may be seen to arise within Fricker's framework once we notice that there is more than one way for a subject to be frustrated in their attempt to reach a correct understanding of a wrong they have suffered. One, manifested in Fricker's central cases, involves the victim using interpretive tools that are inadequate to fully understand as problematic a wrong which they experience. This kind of frustration is felt by the subject and leads to dissonance. Another way, manifested in deception-based hermeneutical injustice, involves the victim coming to what they take to be a genuine, full understanding of a patch of their social experience which they take to be morally non-

\footnotetext{
${ }^{16}$ There may be other instances as well. It has been suggested to me that the forced adoption of Native Canadian children, of Australian aboriginal children and of Argentinian dissenters' children may also ground deception-based injustice. That the social groups to which the children belonged were hermeneutically marginalised is certain. Whether these are genuine cases of deception-based hermeneutical injustice underpinned by the wrong of forced adoption - depends on the plausibility of the claim that these victims were deceived into believing they were not members of the relevant social group. I am sympathetic to the view that at least in some cases this claim is plausible. Thanks to Sean Valles and Peter Sullivan here.
} 
problematic, where (a) such an understanding stems from the deliberate deception orchestrated by a small group of individuals, which effectively conceals from the subject their victimhood and (b) the deception ultimately stems from the hermeneutical marginalisation of a social group to which the subject belongs. In this case, the victim need not experience dissonance, unless and until they come to suspect that they have been deceived.

Deception-based hermeneutical injustice shares with other forms of hermeneutical injustice the primary harm of preventing the victim from understanding an experience which it is in their interests to understand. But it is both less and more damaging than key cases of hermeneutical injustice in the current literature. It is less damaging in the sense that it does not leave the victim in a state of dissonance. Consequently, the victim insofar as they are deceived - does not suffer some of the epistemic harms that according to Fricker (2007: 162-3) stem from dissonance as potential secondary harms of hermeneutical injustice, such as loss of confidence in one's epistemic abilities and loss of knowledge. Nor does this kind of hermeneutical injustice pair up with testimonial injustice to cause pernicious 'runaway credibility deflations' arising when a victim's unsuccessful attempt at communicating an ill-understood wrong causes their hearer to further demote their credibility, due to their unintelligibility. ${ }^{17}$ But deception-based hermeneutical injustice is also, in a sense, more damaging. Precisely because it avoids causing a state of dissonance in its victim, it renders the wrong less visible and the victim unaware, barring substantial investigation, that anything is morally amiss. This in turn makes the moral wrong of IGM and the deception-based hermeneutical injustice it underpins harder to detect and combat: the fight against moral wrongs that ground hermeneutical injustice is typically first kindled by solidarity among victims, consciousness-raising efforts and, fundamentally, the formation of support networks that yield a better group understanding of the wrong in question through discussing and comparing personal experiences. The insidious nature of deception-based hermeneutical injustice is evident in the fact that if victims of deception-based hermeneutical injustice do not know they have suffered IGM, then they have no reason to join forces in order to fully understand the harm they have suffered, to protest it, and to strive for its eradication.

While internalised-misconception hermeneutical injustice is for similar reasons hard to combat, deception-based hermeneutical injustice is in at least one sense even worse. In contributing to IGM victims' ignorance of their status through deception, medical practitioners have represented a powerful obstructive force to victims of IGM banding together. Through their intentional efforts to hide from victims knowledge of IGM, and perhaps as damagingly - to persuade parents to collude in this deception, medical practitioners have deliberately kept at bay the preconditions for combating hermeneutical injustice: the victims' realization of their victimhood. Deception-based hermeneutical injustice requires that its victims be systematically deceived into believing that the obscured underpinning wrong did not occur; and this sort of deception, if it is to be successful, typically involves a relatively powerful group capable of the kind of influence necessary for this deception to persist. In contrast, in cases of internalisedmisconception hermeneutical injustice in the literature we do not typically need to posit a small group of significantly authoritative agents intent on preventing victims from becoming aware of their victimhood. The struggle to overturn deception-based hermeneutical injustice thus faces a distinctive obstacle.

In concluding, I would like to clarify the significance of my discussion to Fricker's account of hermeneutical injustice. In presenting hermeneutical injustice Fricker is clear

\footnotetext{
${ }^{17}$ See Fricker (2007: 159-60), who credits Jones (2002) with the notion of runaway credibility deflations.
} 
that she is interested in outlining central forms of this concept. She is in other words open to the possibility of variant strains of the notion. Consequently, identifying a form of hermeneutical injustice that does not share key characteristics of central forms of hermeneutical injustice discussed by Fricker is not in and of itself a strategy of objection to Fricker's account: even though deception-based hermeneutical injustice does not emerge from the subject's recognisably unsuccessful attempts to understand the moral wrong that grounds it, or from a correct and successful understanding that cannot be communicated, this fact on its own does not threaten Fricker's account as a whole. Fricker can accept deception-based hermeneutical injustice as a variant or noncentral form of hermeneutical injustice, while maintaining that her account remains correct for central forms of hermeneutical injustice such as the one instantiated by the case of Carmita Wood. And in fact, my outline of deception-based hermeneutical injustice is not presented primarily as a criticism. Rather, it represents a foray within the logical space occupied by hermeneutical injustice, and aims to highlight an interestingly different strain illustrated in a concrete manner by real-life cases of IGM. Nonetheless, there is also a critical element to my discussion. Because in deceptionbased hermeneutical injustice key individuals play an essential role in upholding the victim's ignorance of the wrong they have suffered, pressure is placed on Fricker's claim - in principle separable from her definition of hermeneutical injustice - that hermeneutical injustice is a merely structural and therefore blameless wrong. ${ }^{18}$

\section{References}

Alizai N.K., Thomas D.F.M., Lilford R.J., Batchelor A.G.G. and Johnson N. (1999). 'Feminising Genitoplasty for Congenital Adrenal Hyperplasia: What Happens at Puberty?' Journal of Urology 161 (5), 1588-91.

BBC1 Scotland (2011). 'Me, My Sex and I.' 11 November. https:/learningonscreen.ac.uk/ondemand/index. $\mathrm{php} / \mathrm{prog} / 01 \mathrm{E} 37549$.

Conn J., Gillam L. and Conway G.S. (2005). 'Revealing the Diagnosis of Androgen Insensitivity Syndrome in Adulthood.' British Medical Journal 331, 628-30.

Coventry M. (1998). 'The Tyranny of the Esthetic: Surgery's Most Intimate Violation.' On the Issues Online. https://ontheissuesmagazine.com/1998summer/su98coventry.php.

Creighton S.M. (2004). 'Long-Term Outcome of Feminization Surgery: The London Experience.' BJU International 93(3), 44-6.

D'Alberton F. (2010). 'Disclosing Disorders of Sex Development and Opening the Doors.' Sexual Development 4, 304-9.

Davis G. (2014). 'The Power in a Name: Diagnostic Terminology and Diverse Experiences.' Psychology and Sexuality 5(1), 15-27.

Davis G. (2015). Contesting Intersex: The Dubious Diagnosis. New York, NY: New York University Press.

Diamond M. and Beh H.G. (2006). 'Variations of Sex Development Instead of Disorders of Sex Development (Letter to the Editor).' Archives of Disease in Childhood 91(7).

Dotson K. (2012). 'On Limiting Epistemic Oppression: A Cautionary Tale.' Frontiers 33(1), 24-47.

Dreger A. and Herndon A. (2009). 'Progress and Politics in the Intersex Rights Movement: Feminist Theory in Action.' GLQ: A Journal of Lesbian and Gay Studies 15(2), 199-224.

Fricker M. (2007). Epistemic Injustice: Power and the Ethics of Knowing. Oxford: Oxford University Press.

Fricker M. (2013). 'Epistemic Injustice as a Condition of Political Freedom?' Synthese 190, 1317-32.

Fricker M. (2016). 'Epistemic Injustice and the Preservation of Ignorance.' In R. Peels and M. Blaauw (eds), The Epistemic Dimensions of Ignorance, pp. 160-77. Cambridge: Cambridge University Press.

Fricker M. (2017). 'Evolving Concepts of Epistemic Injustice.' In I.J. Kidd, J. Medina and G. Pohlhaus Jr. (eds), The Routledge Handbook of Epistemic Injustice, pp. 53-60. Abingdon: Routledge.

\footnotetext{
${ }^{18}$ I am grateful to audiences at the University of Stirling, Leibniz Universität Hannover, Università degli Studi di Pavia and the University of Glasgow and to my colleagues at the University of Aberdeen for helpful discussion of this paper. Special thanks to Colin Johnston, Peter Sullivan and Sean Valles.
} 
Haslanger S. (ed.) (2012). 'What are We Talking About? The Semantics and Politics of Social Kinds.' In Resisting Reality: Social Construction and Social Critique, pp. 365-80. Oxford: Oxford University Press.

Hester J.D. (2006). 'Intersex and the Rhetorics of Healing.' In S.E. Sytsma (ed.), Ethics and Intersex, pp. 47-71. Dordrecht: Springer.

Human Rights Watch (2017a). 'A Changing Paradigm: US Medical Provider Discomfort With Intersex Care Practices.' https://www.hrw.org/report/2017/10/26/changing-paradigm/us-medical-provider-discomfort-intersex-care-practices.

Human Rights Watch (2017b). "I Want to Be How Nature Made Me”: Medically Unnecessary Surgery on Intersex Children in the US.' https://www.hrw.org/report/2017/07/25/i-want-be-nature-made-me/medicallyunnecessary-surgeries-intersex-children-us.

Jenkins K. (2017). 'Rape Myths and Domestic Abuse Myths as Hermeneutical Injustices.' Journal of Applied Philosophy 34(2), 191-205.

Jones K. (2002). 'The Politics of Credibility.' In L.M. Antony and C.E. Witt (eds), A Mind of One's Own: Feminist Essays on Reason and Objectivity, 2nd edition. Boulder, CO: Westview Press.

Karkazis K. (2008). Fixing Sex: Intersex, Medical Authority and Lived Experience. Durham, NC: Duke University Press.

Kemp S. (2006). 'The Roles of Genes and Hormones in Sexual Differentiation.' In S.E. Sytsma (ed.), Ethics and Intersex. Dordrecht: Springert.

Lee P.A., Houk C.P. and Hughes, I.A. (2006). 'Consensus Statement on Management of Intersex Disorders. International Consensus Conference on Intersex.' Pediatrics 118(2), e488-500.

Maitra I. (2010). 'The Nature of Epistemic Injustice.' Philosophical Books 51(4), 195-211.

Mason R. (2011). 'Two Kinds of Unknowing.' Hypatia 26(2), 294-307.

McEwan I. (1998). Enduring Love. London: Vintage.

Medina J. (2013). The Epistemology of Resistance: Gender and Racial Oppression, Epistemic Injustice, and the Social Imagination. Oxford: Oxford University Press.

Merrick T. (2017). 'From “Intersex" to "DSD": a case of epistemic injustice.' Synthese https://doi.org/10. 1007/s11229-017-1327-x.

Meyer-Bahlburg H.F.L., Migeon C.J., Berkovitz G.D., Gearhart J.P., Dolezal C. and Wisniewski A.B. (2004). 'Attitudes of Adult 46,XY Intersex Persons to Clinical Management Policies.' Journal of Urology 171, 1615-19.

Mills C. (2007). 'White Ignorance.' In S. Sullivan and N. Tuana (eds), Race and Epistemologies of Ignorance, pp. 13-37. New York, NY: State University of New York Press.

Minto C.L., Liao L., Woodhouse C.R.J., Ransely, P.G. and Creighton, S.M. (2003). 'The Effect of Clitoral Surgery on Sexual Outcome in Individuals who have Intersex Conditions with Ambiguous Genitalia: A Cross-sectional Study.' Lancet 361(9365), 1252-7.

Morris S. (2006). 'Twisted Lies: My Journey in an Imperfect Body.' In E. Parens (ed.), Surgically Shaping Children: Technology, Ethics and the Pursuit of Normality, pp. 3-12. Baltimore, MD: Johns Hopkins University Press.

Pohlhaus Jr. G. (2012). 'Relational Knowing and Epistemic Injustice: Toward a Theory of Willful Hermeneutical Ignorance.' Hypatia 27(4), 715-35.

Sanders C., Carter B and Goodacre L. (2011). 'Searching for Harmony: parents' Narratives about their Child's Genital Ambiguity and Reconstructive Genital Surgeries in Childhood.' Journal of Advanced Nursing 67(10), 2220-30.

Sax L. (2002). 'How Common is Intersex? A Response to Fausto-Sterling.' Journal of Sex Research 39(3), 174-8.

Federico Luzzi is a Senior Lecturer at the University of Aberdeen. His research interests primarily lie in epistemology, ethics and the philosophy of sports (and their intersections).

Cite this article: Luzzi F (2021). Deception-Based Hermeneutical Injustice. Episteme 1-19. https://doi.org/ 10.1017/epi.2021.7 